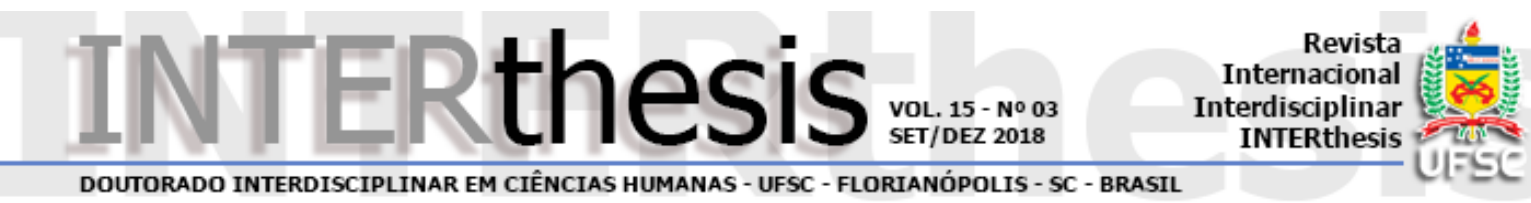

\title{
A TRADIÇÃO DOS CONTOS DE FADA E A SOBREVIVÊNCIA DE MATRIZES CULTURAIS FEMININAS NAS NARRATIVAS CINEMATOGRÁFICAS INFANTIS
}

Heloisa Porto Borges 1

Rodrigo Fonseca Rodrigues ${ }^{2}$

\section{Resumo:}

O principal objetivo deste artigo é o de refletir acerca dos valores culturais que são continuamente reproduzidos pelas narrativas cinematográficas ao longo de gerações. Estes valores que podem ser (re) construídos através das imagens e narrativas, utilizam-se de condutas já legitimadas socialmente como elos mediadores da memória coletiva, reconectando o passado ao contemporâneo. Ao analisarmos historicamente as produções cinematográficas dos estúdios Disney e suas personagens de princesas, percebemos que, embora uma desconstrução de estereótipos femininos possa ser evidenciada, persistem alguns valores tradicionais, que podem ou não ser ressignificados à medida em que a mulher consegue se emancipar culturalmente.

Palavras-chave: Matrizes Femininas. Princesas. Contos de Fada. Narrativas Cinematográficas.

\section{INTRODUÇÃO}

A infância moderna e suas formas de entretenimento e consumo estão desde o início do século XX entrelaçadas à magia do enredo e aos personagens que fazem parte das produções cinematográficas infantis. Inicialmente reconhecido como Disney Brothers Studio, os estúdios “Disney” foram os primeiros a se diferenciaram no mercado cinematográfico ao desenvolverem, ainda em 1923, suas primeiras animações destinadas especificamente ao gênero infantil. Martin-Barbero (2009) enfatiza que o gênero não deve ser percebido apenas como uma classificação da narrativa audiovisual, mas como um mecanismo pelo qual se constrói o reconhecimento. Sob este ponto de vista é que podemos dizer que esta segmentação foi imprescindível ao direcionamento e ao reconhecimento dos estúdios Disney dentro do mercado cinematográfico mundial.

\footnotetext{
1 Mestre em Estudos Culturais Contemporâneos pela Universidade da Fundação Mineira de Educação e Cultura, Belo Horizonte, MG, Brasil E-mail: heloisapborges@hotmail.com

2 Doutor em Comunicação e Semiótica pela Pontifícia Universidade Católica de São Paulo. Pósdoutoramento em Ciências da Linguagem, pela Universidade Nova de Lisboa, Portugal. Professor Adjunto da Universidade da Fundação Mineira de Educação e Cultura, Belo Horizonte, MG, Brasil Email: rfonseca@fumec.br
} 
Visto inicialmente como arte popular, nômade e plebeu, onde se protagonizavam os melodramas sociais sobre os teatros de arena (principalmente através de atrações circenses), o espetáculo da interpretação só se modernizou a partir de sua transposição para a sala escura, quando o aperfeiçoamento técnico transformou aquilo que o olho vê em espetáculos tecnicamente mediados, destinados principalmente ao consumo coletivo das massas. O cinema, portanto, estimulou uma nova forma de consumo e de mercado, em que o comércio do imaginário além de interligar uma cadeia econômica de interesses, passou a influenciar nas relações entre os indivíduos e na sua percepção acerca de si mesmos e da própria sociedade. As relações mediadas por imagens se tornaram estímulos ao consumo, os personagens imaginários passaram também a ganhar significações culturais. Dentro deste processo, os estúdios cinematográficos da Disney também passaram a reforçar modelos e padrões de condutas sociais, tendo como elemento "chave" a reformulação de personagens que possibilitem uma conexão épica mantendo uma interlocução entre gerações.

As personagens de princesas como produtos de consumo se inseriram dentro desse sistema e se mostraram extremamente lucrativas, sendo inclusive transformadas em bonecas, mochilas, estojos, merendeiras e outros materiais dentro de uma franquia própria, denominada "princesas Disney". Este reencanto ao mundo maravilhoso das princesas nos leva a crer que os modelos femininos estão associados acima de tudo a questões subjetivas de conduta e admiração, e que nos conectam à travessia de vida das próprias personagens. Este artigo, portanto, pretende ressaltar a relação existente entre as personagens de princesa, a tradição e os discursos sociais em que elas se inserem, além de buscar compreender os elementos imagéticos que caracterizam estas personagens ao longo da história e a relação projetada entre elas e as mulheres contemporâneas.

\section{A TRADIÇÃO DOS CONTOS DE FADA E SUA RELEVÂNCIA COMO MANTENEDORES DE VIRTUDES DO ESPÍRITO FEMININO.}

Originária do latim traditio que remete ao conceito de "passar adiante", a tradição é relacionada à transmissão de costumes, lendas, hábitos ou performances que são passados de geração em geração através dos tempos. Sob este viés, a tradição se relaciona à perpetuação cultural, ou seja, às experiências compartilhadas entre gerações. Embora na antiguidade, o termo "cultura" se visse associado 
principalmente a um processo de produção feudal, hoje ela emerge juntamente com a etnologia para ser utilizado como definição para uma soma de experiências coletivas, sendo que estas experiências podem ser de natureza material, mental, e também social. ${ }^{3} \mathrm{Um}$ fato interessante é que, quanto mais antigas e difundidas são estas tradições, mais elas se transformam em crenças culturais inquestionáveis, as quais muitas vezes foram adotadas como verdades absolutas. Manuel Castells (2001) menciona que a tradição como elemento cultural passa a ser evidenciada quando estruturas enraizadas que servem como base para a construção das identidades são criadas, e mais do que isto, quando estas são continuamente recriadas.

A partir dessa percepção é que procuramos resgatar na tradição dos contos de fadas essas mulheres que são constantemente evidenciadas, e de que forma elas corroboram para a institucionalização de modelos de conduta. Muitas vezes tidas como protagonistas, a ênfase ao feminino nos contos se justifica, segundo Nelly Coelho (1991), pela sua origem celta, onde diferentemente da cultura de outros povos, as mulheres possuíam uma maior evidencia social, e status relacionado ao "poder", ao cultivo e a procriação. As fadas no folclore Europeu Ocidental apresentam-se como mulheres de grande beleza, providas, sobretudo, de poderes sobrenaturais. Porém, quando utilizam destes poderes de forma diabólica, as fadas se transformam em pecadoras, ou seja, em bruxas, reforçando a dicotomia feminina entre boa e má, heroína e vilã, santa e pecadora. As personagens de princesas são constantemente associadas aos papéis de heroínas dentro das narrativas, enquanto a bruxa como um ser poderoso, mas perverso, se projeta no imaginário como uma versão distinta dentro deste universo feminino. Contudo, apesar de sua evidência dentro das estórias, as tradicionais personagens femininas dos contos Ocidentais

\footnotetext{
${ }^{3} \mathrm{Na}$ era moderna, mais precisamente a partir do século XVIII, a cultura foi incorporada a uma ideologia iluminista relacionada à razão, passando a se associar (principalmente na sociedade francesa) às atividades consideradas cultas e eruditas, enfatizando a superioridade de determinados grupos.

No século XIX, o termo "Cultur" passou também a ser utilizado nos países europeus como um sinônimo de "civilização", de organização e progresso social delimitando acima de tudo as fronteiras entre a selvageria dos povos considerados primitivos e o progresso intelectual e humanístico que se apresentava como o único caminho para o desenvolvimento das sociedades. Esta classificação cultural utilizada como forma de estratificação social foi considerada por Thompson (2011) como um elemento extremamente importante na época, pois possibilitou a distinção social entre os valores da nobreza e aqueles pertencentes à burguesia. Aos poucos, o termo que representava a superioridade de grupos sobre outros passou a ser associado não somente às questões de classe, mas passou a ser compreendido também como um termo que incorpora os indivíduos a determinados grupos sociais a partir de elementos identifica tórios que podem ser herdados ou também adquiridos.
} 
(diferentemente dos outros continentes, como é o caso das princesas russas mencionadas por Propp (2002), poucas vezes exercem de fato um protagonismo sobre os seus próprios caminhos ${ }^{4}$. Contando com a própria sorte, na maioria das vezes estas mulheres se deixam levar pelos acontecimentos, sempre em busca de uma salvação para os seus problemas. Neste ponto é importante observarmos a importância do mito cristão como elemento que, associado a determinados arquétipos, contribuiu e ainda contribui para a elaboração de modelos de subordinação e padrões de representações femininas.

Historicamente, a igreja tem um importante papel nessa construção, ao dividir a imagem da mulher na ambiguidade entre a persona de Eva e Maria, separando a santa da pecadora. Contudo, foi frente à crise dos valores clássicos franceses e à necessidade política de reforços religiosos durante a monarquia de Luís XIV (o Rei Sol) que segundo Coelho reiniciou-se, na Europa, um movimento de purificação dos costumes primitivos e ritualísticos através de regras de conduta, pelas quais a mulher passou a ser rigorosamente doutrinada dentro de uma conduta de virtudes próprias direcionadas ao espaço privado do lar. Quando a cultura como tradição passou a ser rearticulada como forma de organização social e educacional é que os Contos de Fada ganharam, portanto, um caráter moralizante, se associando, para isso aos valores religiosos da época.

Denominados como conte de fées, os contos populares originários da Índia se "enculturaram" através dos séculos com a fonte latina e céltico-bretã a partir da oralidade, e foram recuperados no século XVII como arte literária por Charles Perrault (1987), apud Propp (2002). Ao percorrer os vilarejos na Europa, Perrault (1987) passou a registrar as estórias guardadas na memória do povo (os contos), adaptando-as estrategicamente com o intuito de passar exemplos e ensinar valores morais para aqueles que os ouviam. Isto porque os contos de fada tal como os conhecemos na literatura atual são muito diferentes das estórias contadas nos campos ou nas reuniões sociais daquela época. Originalmente concebidos como entretenimento para adultos, estas estórias eram compartilhadas nos mais diversos ambientes sociais, e possuíam uma forte associação com os problemas da época,

\footnotetext{
${ }^{4}$ Propp (2002), em seu livro As raízes históricas do Conto Maravilhoso ao analisar as princesas dos contos folclóricos russos, enxerga nestas personagens características arquetipais ambíguas. $\mathrm{O}$ autor (2002, p. 365) reforça que embora seja vista como uma noiva fiel e mulher paciente, as princesas nos contos russos constantemente exibem outra face, "às vezes a princesa é descrita como um bogatir, uma guerreira hábil no tiro com arco, na corrida, monta a cavalo; sua hostilidade com relação ao pretendente assume a forma de uma competição declarada com ele".
} 
como a fome, a repressão feminina, a morte infantil, além de retratar também questões sexuais como adultério ou incestos. Cashdan menciona que:

\begin{abstract}
Muitos dos primeiros contos de fada incluíam exibicionismo, estupro e voyeurismo. Em uma das versões de Chapeuzinho Vermelho, a vovozinha faz um strip-tease para o lobo, antes de pular na cama com ele. Numa das primeiras interpretações de A bela adormecida, o príncipe abusa da princesa em seu sono e depois parte, deixando-a grávida. $E$ no conto $A$ Princesa que não conseguia rir, a heroína é condenada a uma vida de solidão porque, inadvertidamente, viu determinadas partes do corpo de uma bruxa. (CASHDAN, 2000, p. 20).
\end{abstract}

Na própria história verídica de Bela Adormecida, Tália (como é denominada pelo escritor Giambattista Basile e comentado no texto de Borges (2016)) é estuprada pelo rei e acaba dando à luz a um casal de gêmeos. Foi Perrault (1987), apud Propp (2002), que resgatou estas expressões folclóricas populares transmitidas oralmente durante séculos, suavizando seu caráter sexual original, utilizando-se de metáforas para educar seu público, advertindo, sobretudo às jovens camponesas sobre o risco da sedução, o controle dos corpos, e a necessidade de vigilância. Cadermatori (1986, p. 36) reforça que é "por meio dessas narrativas curtas, que o leitor ou ouvinte deverá assimilar ensinamentos religiosos, éticos e, até mesmo, sobre sexualidade, constituindo uma arte moralizante através de uma literatura pedagógica". Em a menina do gorro vermelho, também conhecida como a "Chapeuzinho Vermelho", por exemplo, o caráter moralizante é reforçado na conclusão da estória, e embora apresente subjetivamente alguns traços de sexualidade entre a figura do lobo ao "devorar" a garota, há uma tentativa em advertir as moças sobre os perigos contidos nos galanteios masculinos.

Vê-se aqui que crianças jovens, sobretudo moças belas, bem-feitas e gentis, fazem muito mal em escutar todo o tipo de gente; e que não é coisa estranha que o lobo tantas delas coma. Digo o lobo, porque nem todos os lobos são do mesmo tipo. Há-os de um humor gracioso, subtis, sem fel e sem cólera, que - familiares complacentes e doces - seguem as jovens até as suas casas, até mesmo aos seus quartos; mas ai! Quem não sabe que estes lobos delicotes são de todos os lobos os mais perigosos. (PERRAULT, 1987, p. 22)

Já no conto de Cinderela, Perrault enfatiza a virtude da doçura como um diferencial feminino:

É um tesouro para a mulher a formosura/

Que nunca nos fartamos de admirar/

Mas aquele dom que chamamos doçura/

Tem um valor que não pode estimar.

Foi isso que Cinderela aprendeu com a madrinha/

Que a ensinou e instruiu com um zelo tal/

Que um dia finalmente, dela fez uma rainha/ 
Beldade, ela vale mais do que roupas enfeitadas.

Para ganhar um coração, chegar ao fim da batalha/

A doçura é que é a dádiva preciosa das fadas/

Adorne-se com ela, pois que esta virtude não falha.

(PERRAULT citado por MACHADO, 2010, p. 30).

Portanto, a doçura, o recato, o amor, a formosura, a caridade e a obediência são retratados como virtudes femininas que devem ser cultivadas como regras de conduta. E é nesse sentido que, indiretamente, as personagens tradicionais de princesas corroboraram em nível religioso com um esforço da igreja e também do Estado em propagar a valorização social da mulher por meio da conduta familiar. $O$ culto à Maria, mãe de cristo e modelo feminino "exemplar" de mulher pura, devota e acima de tudo sofredora, é o que inspira o sofrimento como necessidade, e a resignação como caminho para a eterna salvação. Bettelheim (2002, p. 14) comenta que, como "a maioria dos contos de fadas se originou em períodos em que a religião era parte muito importante da vida; eles lidam diretamente ou por inferência, com temas religiosos". Nesse sentido, é importante termos consciência que essas matrizes culturais que estão historicamente sedimentadas no coletivo, não se referem a algo biologicamente herdado, mas historicamente construído e reconstruído de acordo com os interesses sociais, conforme defendido por Simone de Beauvoir:

Ninguém nasce mulher, torna-se mulher. Nenhum destino biológico, psíquico, econômico define a forma que a fêmea humana assume no seio da sociedade; é o conjunto da civilização que elabora esse produto intermediário entre o macho e o castrado que qualificam de feminino. (BEAUVOIR, 1967, p.9).

Percebemos, portanto, a contribuição dos contos neste processo de intermediação de interesses e seu importante papel para a construção das identidades femininas da época. O imaginário favorece a estruturação das ideologias quando elabora modelos mentais de uma realidade exterior em que as representações carregadas de afetividade e de emoções impõe sentidos definidos, deturpando o real. E é neste ponto que Trindade e Laplatine (1997) nos chamam a atenção para as criações de novos deuses, que são estruturados articulando ideologicamente a religião com fatores socioculturais, reinterpretando as tradições. A convergência entre a literatura e o cinema favoreceu esta constante releitura e readaptação de papeis femininos, para que se tornassem cada vez mais 
verossímeis e mais comerciais, mas sem perder, portanto, sua verdadeira essência, que era ideológica.

\section{A EVOLUÇÃO DOS ESTEREÓTIPOS NAS PERSONAGENS DE PRINCESAS DISNEY, E A SOBREVIVÊNCIA NAS IMAGENS.}

Fernanda Breder (2013) desenvolveu um interessante trabalho sobre a representação feminina nos contos de fada a partir dos estereótipos das princesas nos filmes Disney. A autora coloca em evidência a relação entre as personagens de princesas e as lutas feministas, argumentando que estas personagens desde os primórdios, representam, acima de tudo, o reflexo da mulher do período histórico em que foram criadas, ou recriadas. Desta forma, Breder descreve a evolução nos estereótipos destas personagens, que foram se tornando cada vez mais independentes à medida que a própria percepção das mulheres sobre seu papel social foi sendo alterado. E neste contexto de transição histórica, a autora classifica as personagens de princesas entre clássicas, rebeldes e contemporâneas, construindo uma evolução das personagens femininas, desconstruindo a ideia de que os estúdios Disney estimulem a construção de um imaginário monolítico sobre o papel feminino.

Para Breder (2013), as princesas clássicas são aquelas personagens reconhecidas como princesas tradicionais, por serem as que carregam consigo 0 maior número de símbolos característicos da realeza (como coroa, castelo e vestidos) sendo também as mais lembradas ao longo das gerações. Produzidas entre 1937 e 1959, as princesas Branca de Neve, Cinderela e Aurora são caracterizadas como jovens, e mantêm modelos de beleza peculiares, que despertam o desejo dos homens, fulminando a inveja nas mulheres, principalmente em suas madrastas. Aliás, Branca de Neve quase foi assassinada, e Cinderela foi cuidadosamente enclausurada exclusivamente por conta de sua beleza física. Ou seja, estas personagens estimulam um interesse pelo culto a beleza, reforçando padrões estéticos ocidentais que são muitas vezes inalcançáveis. E sob este viés, a valorização da mulher obrigatoriamente transpassa pela sua aparência.

No que diz respeito à conduta, as princesas clássicas devem servir de modelo, assim, se expressam através de uma fala doce, aveludada e retratam gestos delicados. Com voz suave, cantam e "encantam", mantendo grande proximidade com a natureza e com os animais. De forma geral, estas personagens 
se apresentam como pessoas frágeis, solidárias e complacentes, mas fatalmente sofredoras e solitárias, sempre à espera de algo ou alguém que possa transformar os acontecimentos de sua vida. Por conta disto, é que a figura masculina constantemente se transforma em herói, e que como príncipes salvadores as resgatam do sofrimento, associando a felicidade feminina com a presença masculina, que culminará no casamento, selado por um beijo. Se analisarmos as princesas clássicas produzidas na primeira metade do século XX podemos confirmar através das imagens esta percepção:

Figura 1 - Fragilidade

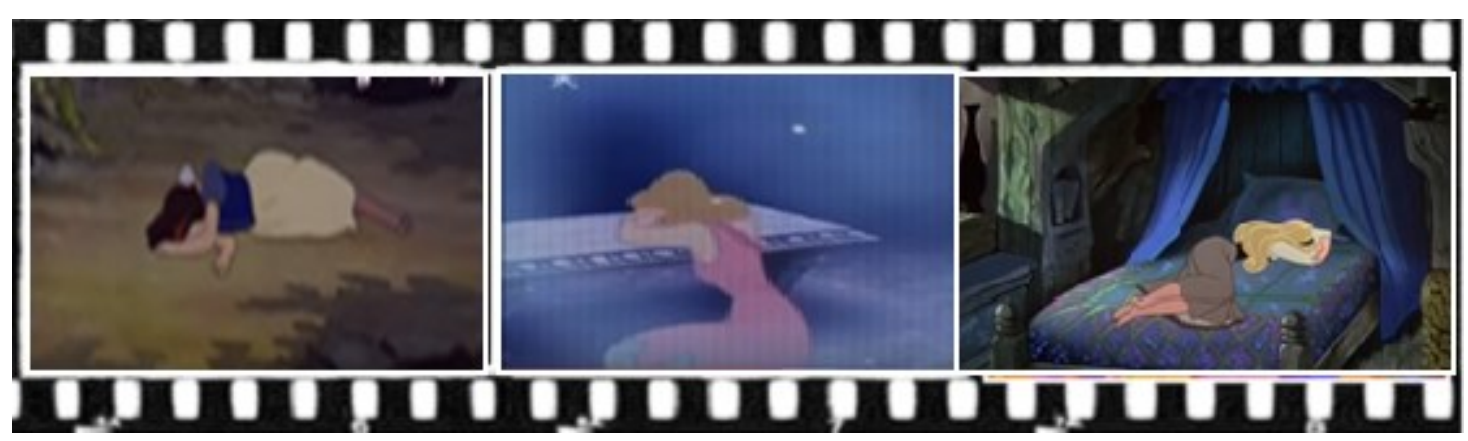

Filmes: Branca de Neve (1937) - Cinderela (1950) - A Bela Adormecida (1959)

Figura 2 - 0 amor romântico

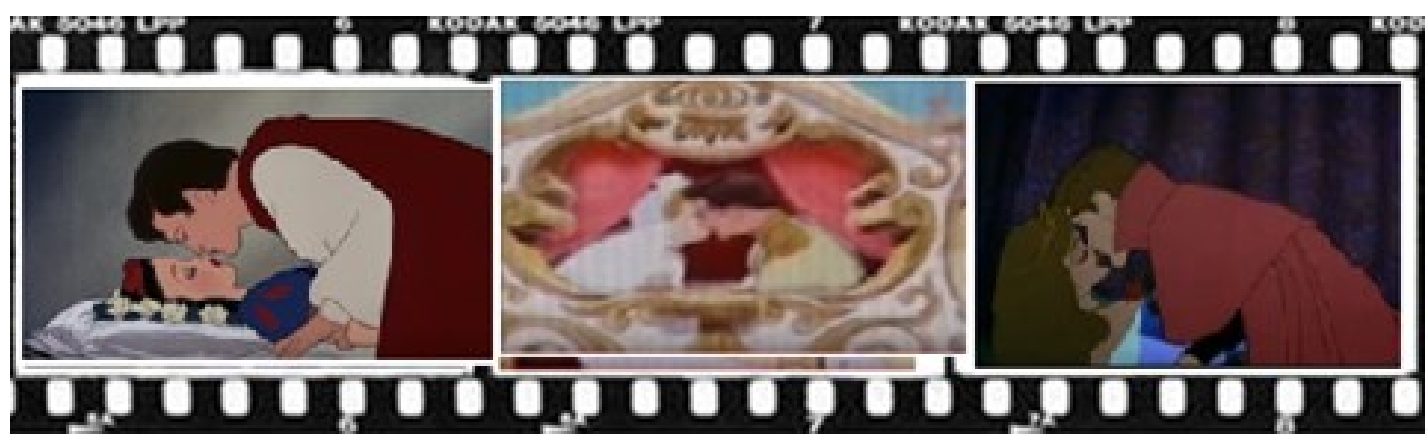

Filmes: Branca de Neve (1937) - Cinderela (1950) - A Bela Adormecida (1959)

No que diz respeito à suas habilidades, essas personagens, embora motivadas por razões diferentes, também demonstram capacidade de organização do lar, e grande competência no que diz respeito aos afazeres domésticos e no cuidado com a família em que estão acolhidas. Produzidas entre 1937 e 1959, as princesas clássicas na verdade se enquadram no modelo feminino das mulheres brancas de classe média alta da época, em que o espaço privado do lar era sua única responsabilidade. Historicamente rotuladas como seres desprotegidos e emocionalmente vulneráveis aos olhos de uma sociedade patriarcal, percebe-se na década de 1950 um forte estímulo midiático para manter a relação de subordinação 
da mulher associando-a com a funcionalidade de mantenedora do lar. As campanhas de eletrodomésticos associavam a máquina de lavar, geladeira e telefone aos artigos de luxo, e assim viravam rapidamente objetos de desejo, relacionando a felicidade feminina ao espaço privado. Alves e Pitangui (1982, p. 50) mencionam que "as mensagens veiculadas pelos meios de comunicação enfatizam a imagem da rainha do lar, exacerbando-se a mistificação do papel da dona-decasa, esposa e mãe".

Figura 3 - Afazeres Domésticos

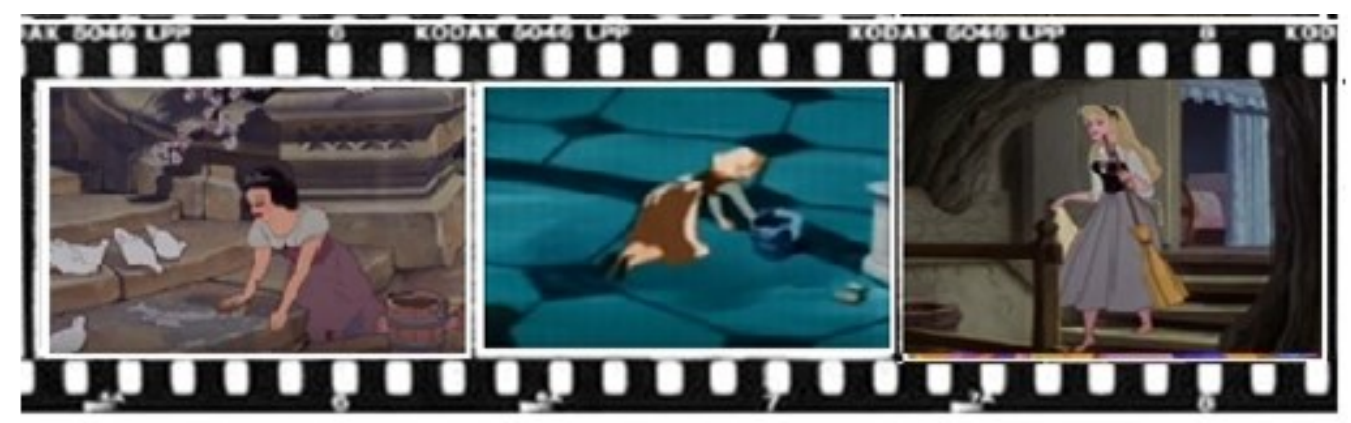

Filmes: Branca de Neve (1937) - Cinderela (1950) - A Bela Adormecida (1959)

O sufrágio feminino e o reconhecimento de sua cidadania pelas próprias mulheres foram fundamentais para que o jogo se invertesse, desencadeando um esforço social para mantê-las sob controle, e para isso, a ajuda dos meios de comunicação e do cinema se tornaram essenciais para um processo discursivo que enfatiza a importância do lar, da família e do casamento com um bom partido, que pudesse lhes dar o mínimo de estabilidade financeira.

Foi somente na década de 1960 que a luta feminista se reorganizou, trazendo novos questionamentos políticos quanto à estas formas tradicionais de convívio social. "O pessoal é político" procurou justamente trazer consciência quanto à necessidade da figura feminina também no espaço público, preocupando-se principalmente com questões de igualdade e o fim da discriminação refletida nas estruturas de poder sexistas. Durante esse conturbado período de tentativa de mudança cultural, não houve nenhuma produção com princesas como protagonistas. Afinal, para que novas formas de representações fossem reproduzidas sem comprometer o lucro capitalista da corporação, seria necessário a maior compreensão acerca destas mudanças sociais e de como as próprias mulheres gostariam de ser representadas.

Foi somente no final dos anos 1980 e início dos anos 1990, quando as mulheres já se viam atuando efetivamente no espaço público através de um 
posicionamento (ainda que discriminatório e gradual) no mercado de trabalho e na política, que estas personagens ressurgiram com uma nova roupagem e em um importante momento de transição no que diz respeito às lutas feministas. Conscientes das diferenças presentes entre as próprias mulheres e guiadas pelo desejo de manterem sua própria liberdade e independência, é que as princesas rebeldes se incorporam na indústria cinematográfica sendo produzidas entre $1989 \mathrm{e}$ 1998. Elas ressurgem, reforçando a dicotomia naturalmente existente no próprio feminino e reivindicando seus papéis dentro da sociedade, apresentando ao público infantil as variadas possibilidades de se ser mulher.

Com Ariel, Jasmine, Pocahontas e Mulan surgem variadas representações dentro do contexto de realeza, reforçando a dicotomia existente entre os estereótipos femininos. Estas personagens se tornam extremamente relevantes para a percepção de grupos sociais e culturais distintos, proporcionando uma maior compreensão sobre a diversidade de raças, etnias e costumes entre os povos, além de trabalhar, ainda na infância, a importância da aceitação das diferenças. Além disso, ao se apresentarem como garotas de personalidade forte e decididas, as princesas rebeldes reforçam um papel feminino mais igualitário, em que a mulher assume seu papel social, passando a ser a responsável pela escolha do seu próprio destino. Mulan inclusive, ao decidir ocupar um lugar no exército, se disfarça de homem, treinando duro para se tornar um bom soldado. Estas características que são apresentadas ao longo de suas ações, fazem com que essas princesas se diferenciem do modelo feminino tradicional de submissão, nos fazendo compreender que o papel feminino, de fato, não precisa ser monolítico.

É nesse processo evolutivo que diz respeito às atitudes femininas que as princesas contemporâneas da nova era Disney ressurgem em pleno século XXI com traços característicos da mulher moderna. Denominadas por Gilles Lipovetsky (2000) como "terceira mulher", a mulher contemporânea é aquela que, aos poucos, se desvencilha de sua total dependência da figura masculina, conquistando seu próprio espaço na vida pública, desvitalizando-se também do ideal da mulher do lar. Seria a eclosão de um novo papel social feminino a partir da compreensão da mulher sobre o seu próprio ser, do seu próprio corpo e dos seus direitos. A liberdade sexual, o direito ao voto e aos estudos e o controle da maternidade foram essenciais para a construção da autonomia presente nessa nova mulher. Nesse contexto, as princesas ressurgem em circunstâncias pouco contextualizadas em produções 
infantis. A princesa Tiana se consagrou como a primeira princesa afro-americana nos Estúdios Disney. De origem humilde, a garota trabalhadora sempre se esforçou para juntar dinheiro e montar seu próprio restaurante. Embora interpretado por muitos como uma personagem que reflete a independência feminina, ascensão ao mercado de trabalho e empreendedorismo da mulher, Tiana materializa, acima de tudo, o reflexo histórico das mulheres pobres e negras que por necessidade, abandono ou negligência, há muito tempo já exercem atividades fora do lar, inicialmente nos campos, nas oficinas e nas fábricas.

Já Rapunzel nasceu como princesa, mas ao contrário de seu conto de origem, ela não é vitimada e não se coloca como uma donzela em perigo. Embora carregue em seus cabelos mágicos um poderoso antídoto da juventude, sua personagem questiona subjetivamente 0 culto excessivo aos produtos rejuvenescedores milagrosos, sendo extremamente autentica e determinada. Tendo como aliado uma figura masculina, embora apaixonada, ela não se subordina, se colocando como igual. Merida é uma princesa "valente" e também reconhecida como a princesa dos cabelos rebeldes, descontruindo o padrão de beleza e comportamento relacionado às princesas clássicas. Ela tem uma personalidade forte e nega a enquadrar-se nos padrões de conduta ao quais sua mãe se dispõe a educá-la, questionando algumas tradições e recusando-se a casar-se com o pretendente escolhido por sua família. O ponto central da trama se apresenta pelo conflito entre Merida (a guerreira do arco e flecha) e sua mãe, uma mulher comportada, que defende a etiqueta como obrigação social feminina, além do casamento como objetivo para uma mulher.

Embora a princesa Frozen tenha sido a produção mais recente com princesas como protagonista nos estúdios Disney, o filme também reforça esta dualidade feminina por meio de duas irmãs. Elza ganhou maior notoriedade por conta de seu poder congelante, mas é a que mais se assemelha fisicamente às princesas clássicas. Porém Anna se apresenta como a desvabradora, com atitudes mais condizentes a uma princesa contemporânea.

No contexto geral dessas produções, conseguimos verificar de fato, esta evolução nas habilidades, com maior liberdade feminina quanto à escolha de seus caminhos, e um maior desprendimento à obrigação matrimonial no que diz respeito à sua própria felicidade. Contudo, apesar de suas atitudes, não podemos negar que a terceira mulher ainda assume um conjunto de "funções tradicionalmente femininas" 
conforme mencionado por Lipovetsky (2000). São funções que estão tão enraizadas em sua essência cultural que deixam rastro, teimando em não desaparecer. Ao analisar as princesas dos contos folclóricos russos, Vladimir Propp (2002) reforça que as elas constantemente exibem sua outra face, a de mulher guerreira e hábil apresentando em alguns momentos até certa competição em relação à figura masculina, mas ainda são vistas como uma noiva fiel e mulher paciente.

Nesse contexto é que embora falemos de evolução tendo o estudo de Breder (2013) como referência, não podemos desconsiderar aquilo da tradição cultural que ainda permanece. Essa ambivalência como propriedade intrínseca do eterno feminino vem sendo cada vez mais camuflada, procurando não se evidenciar pelo discurso oral. Contudo, ele continua a se ancorar nas imagens, que na maioria das vezes resgatam a correlação entre a mulher clássica e a contemporânea, entre a dama destemida e a frágil, entre a princesa independente e a apaixonada, reconciliando, portanto, o novo com o passado. É desta forma que as funções e papéis tradicionais se perpetuam, combinando-se de maneira inédita com papéis considerados modernos.

Didi-Huberman (2013) denomina como "cultura visual" justamente este discurso próprio das imagens, que é quando sem a necessidade de um discurso falado, conseguimos compreender a mensagem. Neste contexto, um rosto, uma roupa, um corpo, um gesto ou um simples objeto contido em uma imagem representa um discurso, que se torna cada vez mais familiar quando suas significações já estão enraizadas no consciente coletivo. O autor comenta que para o historiador de arte Aby Warburg a construção do diálogo entre passado e presente só se torna possível a partir da constante repetição, que no caso das imagens, não necessariamente precisa ter uma forma determinada, bastando trazem referências já residentes em uma memória coletiva. Elementos artísticos ou não, que sejam capazes de despertar a própria Mnemósinea, estimulando percepções que vão além da singularidade de cada um de nós, mas constantemente estimuladas por um pensamento por imagens.

Quando passamos a analisar as produções contemporâneas, encontraremos esta reincidência de imagens no que se refere ao papel social feminino tradicional. A procriação como mantenedor do núcleo familiar, e os cuidados domésticos como virtude da mulher ainda podem ser vistos como um dificultador no que diz respeito ao desvencilhamento dos papéis femininos de submissão que enquadravam as 
mulheres como servas, esposas ou escravas. Mas, se por um lado esta permanência nos diz muito sobre a sociedade, inclusive a americana, que ainda possui um maior apego aos costumes e à unidade familiar tendo como base a religião, ela também nos leva a refletir que a complexidade de papéis fragmentados que rotineiramente resgatam valores tradicionais, na verdade, nos possibilitam fazer novas escolhas. Conforme mencionado por Vaitsman (1994, p.174) "tendo deixado de ser necessariamente mãe e dona de casa, a mulher pode até decidir ser apenas mãe e dona de casa".

Assim, as princesas contemporâneas, de certa forma, ainda assumem seu papel tradicional de cuidadoras dentro da família, resgatando pelas imagens a importância da mulher neste núcleo, tanto como transmissora de afeto, quanto de educadora. Porém, nos levam a crer que, quando conscientes do seu papel, ou seja, quando este é o reflexo de uma escolha e não de uma obrigação, a maternidade tende a ser ressignificada, passando a ser interpretada não como uma obrigação de toda mulher, mas como um processo de aprendizagem, realização pessoal e contribuição social, que não mais é tido como um obstáculo para a sua autonomia individual.

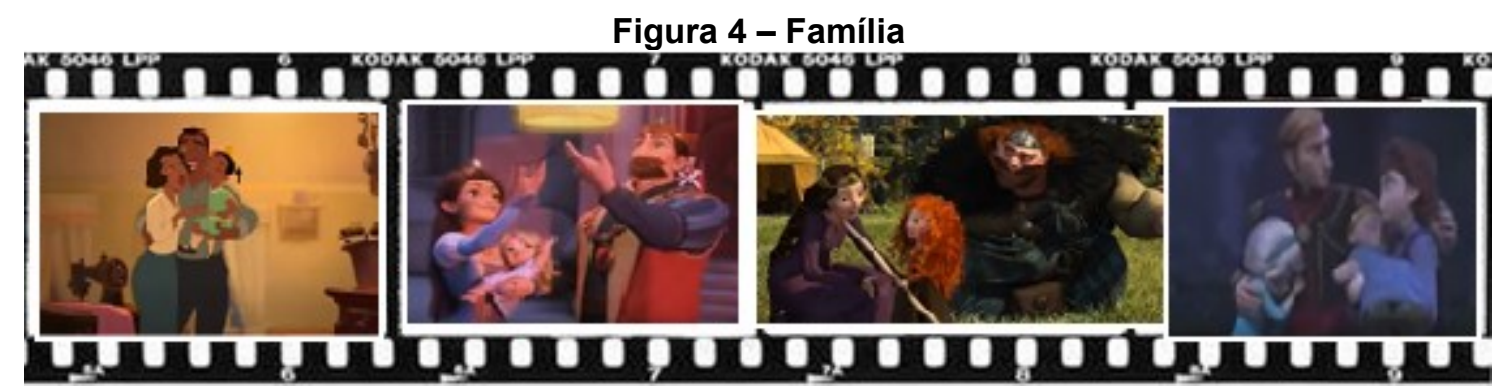

Filmes: A Princesa e O Sapo (2009) - Enrolados (2010) - Valente (2012) - Frozen (2013)

Lipovestsky (2000) comenta também que as tarefas de casa podem ser ressignificadas a partir do momento que passam a ser percebidas não só como uma forma de inferiorização feminina, mas também como oportunidade de se constituir territórios identitários e pessoais, personalizando muitas vezes nestas atividades sua própria maneira de pensar e de agir. Embora não tenhamos percebido no filme Frozen detalhes que abordem as personagens principais executando afazeres domésticos, a maioria das versões contemporâneas ainda associam estas tarefas ao diferencial feminino. 
Figura 5 - Afazeres Domésticos (2)

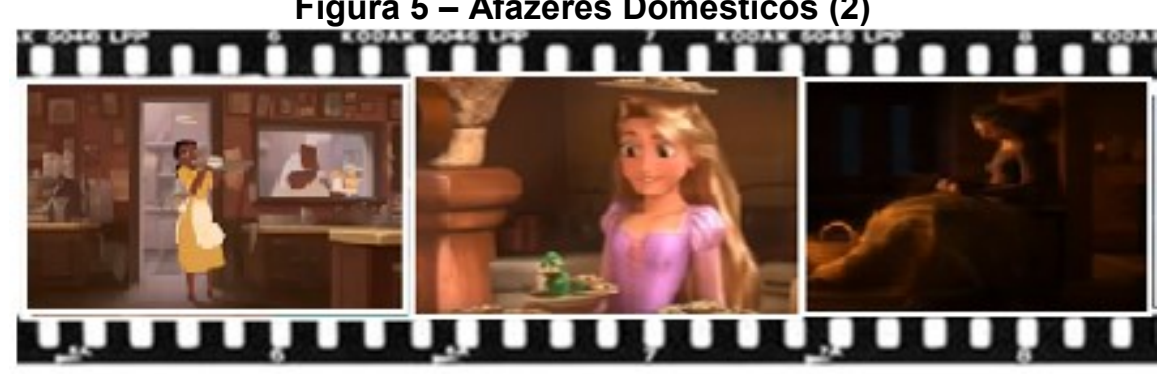

Filmes: A Princesa e O Sapo (2009) - Enrolados (2010) - Valente (2012)

O beijo como ritual pelo qual os laços do amor são selados, simbolizando a união e o princípio de núcleo familiar também permanecem. No caso especificamente do filme Valente, a mãe de Merida é que concretiza este ritual. Contudo, o beijo como união afetiva entre os sexos deixou de ser o caminho salvador para se trazer a mulher de volta à vida, para se tornar um símbolo de amor baseado na livre escolha, já que papéis são cada vez mais baseados na parceria, e não na dominação.

Figura 6 - Amor Romântico (2)

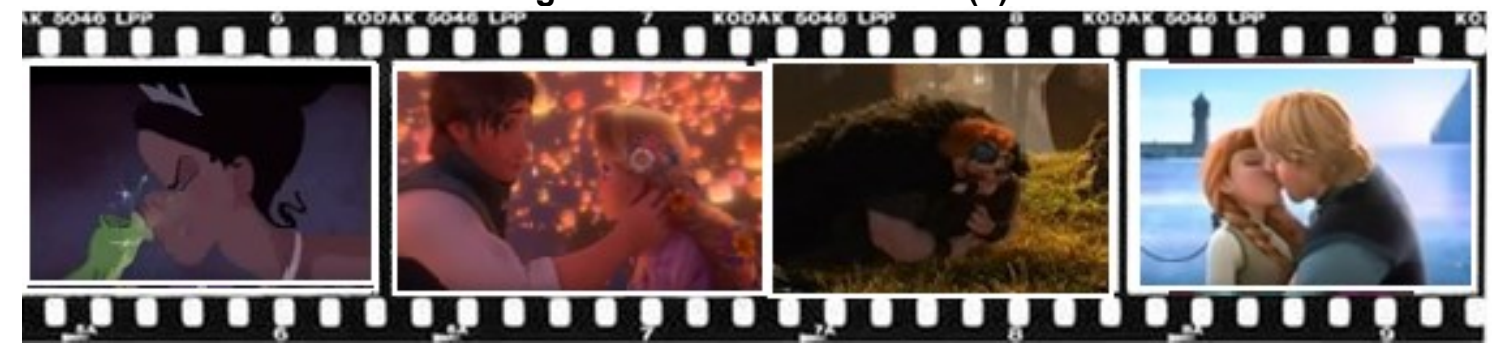

Filmes: A Princesa e O Sapo (2009) - Enrolados (2010) - Valente (2012) -Frozen (2013)

Infelizmente, a fragilidade como reflexo da inconsistência emocional feminina está ainda enraizada na percepção sobre o gênero. A construção de uma mentalidade que acredita que a fragilidade se associa à incapacidade feminina ainda é algo naturalizado, embora tenha sido aos poucos descontruído quando se compreende que os momentos de fraqueza e angústias são inerentes ao ser humano, e faz parte de nossa trajetória de vida, independente do gênero.

Figura 7 - A Fragilidade (2)

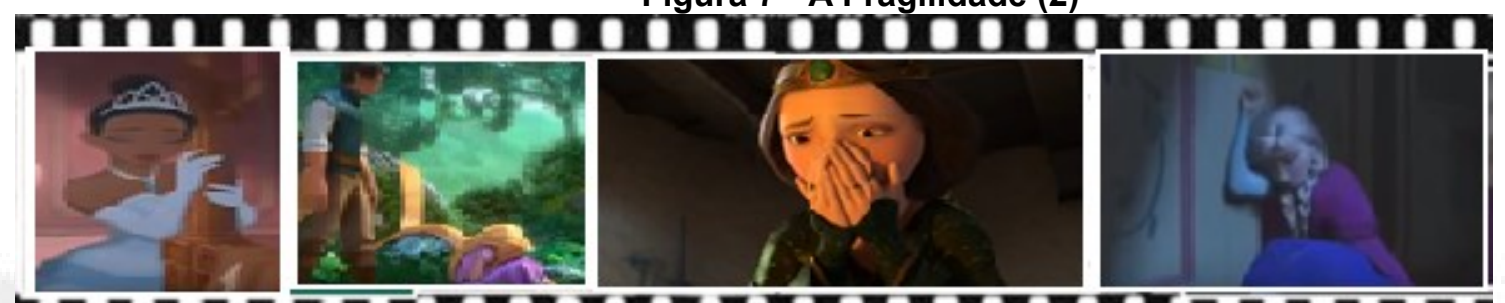

Filmes: A Princesa e O Sapo (2009) - Enrolados (2010) - Valente (2012) - Frozen (2013) 


\section{CONSIDERAÇÕES FINAIS}

Difícil dizer o que é ser mulher, e mais do que isso, de estabelecer qual os papéis são ou devem ser desempenhados por cada uma delas. Afinal, quantas mulheres cabem dentro de uma mesma mulher? O que buscamos com este trabalho foi resgatar historicamente as nuances contidas no próprio feminino, utilizando neste processo as personagens de princesas do cinema infantil Disney como referência. Como personagens constantemente recriadas e que se perpetuam no imaginário a gerações, de várias formas estas mulheres dialogam com o seu público, trazendo intrínseco em suas representações, características que nos permitem identificá-las a partir do próprio contexto da produção ao qual se originam.

Ao analisarmos esse discurso sob um viés histórico, conseguimos perceber de que forma as ideologias se materializam e compreender que os discursos nunca são inéditos, mas que o contexto de produção do qual eles se originam com certeza o é. A dicotomia existencial como nuance contida no próprio feminino independente da época, e que nos é evidenciado por diversos autores como Propp (2002) e Lipovestsy (2000) devem ser consideradas, e embora Breder (2013) busque estabelecer critérios temporais que enquadrem as mulheres e as representações de princesas dentro de um contexto histórico de produção, as imagens nos fazem questionar se de fato cada período histórico possuiu um discurso diferente, ou se de forma velada estes discursos apenas reincidem.

A sobrevivência nas imagens abordada por Didi Huberman e Aby Warburg (2013) nos leva a crer que, apesar de todo um esforço em propagar as personagens de princesas como mulheres modernas e, portanto, desconectadas de um papel tradicional é quase que impossível, uma vez que estes discursos são continuamente perpetuados pelas imagens, resgatando posicionamentos culturalmente já préestabelecido. Contudo, ao analisarmos essa sobrevivência tendo como premissa a impossibilidade de um retrocesso, e a partir da concepção de terceira mulher trazida por Lipovetsky (2000), é que nos damos conta de que o que essas imagens nos possibilitam é uma nova ressignificação para um mesmo discurso. O novo, portanto, não está no que é dito, mas na forma em que é reinterpretado, e essa nova interpretação só se torna possível a partir dos avanços sociais, culturais e históricos diante das diversas facetas existentes e permitidas de se ser mulher. 


\title{
THE TRADITION OF FAIRY TALES AND THE SURVIVAL OF FEMININE CULTURAL MATRICES IN NARRATIVES OF CHILDREN'S FILMS
}

\begin{abstract}
:
The main objective of this article is to reflect about the cultural values that are continually reproduced by cinematographic narratives throughout generations. These values can be (re) constructed per images and narratives, using already socially legitimized behaviors as mediators of collective memory, reconnecting the past to the contemporary time. In historically analyzing the film productions of Disney studios and their princess characters, we realize that although a deconstruction of female stereotypes can be evidenced, there is a premise of traditional values remnants that tend to survive, that may or may not be re-signified as we understand that idealized image of the woman needs to connect to her own experiences and emancipates culturally.
\end{abstract}

Keywords: Female Matrices. Princesses. Fairy Tales. Cinematographic Narratives.

\section{LA TRADICIÓN DE LOS CUENTOS DE HADA Y LA SUPERVIVENCIA DE MATRICES CULTURALES FEMENINAS EN LAS NARRATIVAS CINEMATOGRÁFICAS INFANTILES}

\section{Resumen:}

El principal objetivo de este artículo es el de reflexionar acerca de los valores culturales que son continuamente reproducidos por las narrativas cinematográficas a lo largo de generaciones. Estos valores que pueden ser (re)construidos a través de las imágenes y narrativas, se valen de conductas ya legitimadas socialmente como eslabones mediadores de la memoria colectiva, reconectando el pasado a lo contemporáneo. Al analizar históricamente las producciones cinematográficas de los estudios Disney y sus personajes de princesas, percibimos que, aunque pueda ser evidenciada una desconstrucción de estereotipos femeninos, hay una premisa de remanencias culturales que tienden a sobrevivir, pudiendo ser resignificadas (o no) a medida que la mujer connsigue emanciarse culturalmente.

Palabras clave: Matrices Femeninas. Princesas. Cuentos de Hada. Narrativas Cinematográficas. 


\section{REFERÊNCIAS}

ALVES, B.M. PITANGUY, J. O que é feminismo. São Paulo: Editora Brasiliense, 1982.

BEAUVOIR, Simone. O segundo sexo II - a experiência vivida. 2. ed. Tradução de Sérgio Milliet. São Paulo: Difusão Europeia do Livro,1967.

BETTELHEIM, Bruno. A psicanálise dos contos de fadas. Rio de Janeiro: Paz e Terra, 2002.

BORGES, Juliana. Uma bela muito sofrida. A verdade por trás dos contos de fada. Carapicuíba, SP, ano 2, n.3, p.6-9,Editora Alto Astral, 2016.

BREDER, Fernanda. Feminismo e príncipes encantados: a representação feminina nos filmes de princesa da Disney. Rio de Janeiro: Universidade Federal do Rio de Janeiro - UFRJ, Escola de Comunicação - ECO, 2013.

CADEMARTORI, Ligia.O que é literatura infantil. São Paulo: Brasiliense, 1987.

CASHDAN, Sheldon. Os sete pecados capitais nos contos de fadas: como os contos de fadas influenciam nossas vidas. Rio de Janeiro: Campus, 2000.

CASTELLS, Manuel. O poder da identidade. São Paulo: Paz e Terra, 2001.

COELHO, Nelly. O conto de fadas. São Paulo: Ática, 1991.

DIDI-HUBERMAN, Georges. A imagem sobrevivente: história da arte e tempo dos fantasmas segundo Aby Warburg. Rio de Janeiro: Contraponto, 2013.

LIPOVETSKY, Gilles. A terceira Mulher. Permanência e revolução do feminino. Maria Lucia Machado (trad.), São Paulo: Companhia das Letras, 2000.

MACHADO, Ana Maria. Os contos de fada de Perrault, Grimm, Andersen e outros. Zahar, 2010.

MARTIN-BARBERO, Jesús. Dos meios às mediações: comunicação cultura e hegemonia. Rio de Janeiro: UFRJ, 2009. 
PERRAULT, Charles. Contos de Perrault. Belo Horizonte: Editora Itatiaia, 1987.

PROPP, Vladimir. As raízes históricas do conto maravilhoso. São Paulo. Martins Fontes, 2002.

TRINDADE, L; LAPLATINE, F. O que é imaginário, São Paulo, Brasiliense, 1997.

VAITSMAN, Jeni. Flexíveis e plurais: identidade, casamento e família em circunstâncias pós-modernas. Rio de Janeiro: Editora Rocco, 1994.

\section{FILMOGRAFIA}

A Bela Adormecida (Sleeping Beauty). Direção: Clyde Geronimi, Les Clark, Eric Larson e Wolfgang Reitherman. Produção: Walt Disney. Walt Disney Productions, 1959. $75 \mathrm{~min}$, cor.

A Bela e a Fera (Beauty and the Beast). Direção: Gary Trousdale e Kirk Wise. Produção: Don Hahn. Walt Disney Pictures, 1991. 84 min, cor.

A Branca de Neve e os Sete Anões (Snow White and the Seven Dwarfs). Direção: David Hand, William Cottrell, Wilfred Jackson, Larry Morey, Perce Pearce e Ben Sharpsteen. Produção: Walt Disney. Walt Disney Productions, 1937. 83 min, cor.

A Pequena Sereia (The Little Mermaid). Direção: Ron Clements e John Musker. Produção: John Musker e Howard Ashman. Walt Disney Pictures, 1989. 82 min, cor.

A Princesa e o Sapo (The Princess and the Frog). Direção: Ron Clements e John Musker. Produção: Peter Del Vecho e John Lasseter. Walt Disney Pictures, 2009. 97 min, cor.

Aladdin. Direção: Ron Clements e John Musker. Produção: Ron Clements e John Musker. Walt Disney Pictures, 1992. 90 min, cor.

Cinderela (Cinderella). Direção: Clyde Geronimi, Hamilton Luske e Wilfred Jackson. Produção: Walt Disney. Walt Disney Productions, 1950. 74 min, cor.

Enrolados (Tangled). Direção: Nathan Greno e Byron Howard. Produção: Roy Conli, John Lasseter e Glen Keane. Walt Disney Pictures, 2010. 100 min, cor.

Frozen - Uma Aventura Congelante. Direção: Jennifer Lee E Chris Buck. Produção: Peter Del Vecho e John Lasseter. Walt Disney Pictures, 2014. 1h 42min, cor.

Mulan. Direção: Tony Bancroft e Barry Cook. Produção: Pam Coats. Walt Disney Pictures, 1998. $87 \mathrm{~min}$, cor. 
Pocahontas. Direção: Mike Gabriel e Eric Goldberg. Produção: James Pentecost. Walt Disney Pictures, 1995. 81 min, cor.

Valente (Brave). Direção: Mark Andrews e Brenda Chapman. Produção: Katherine Sarafian. Pixar Animation Studios, 2012. 93 min, cor. 